\section{European research centres may have to pay their way}

\section{London}

Proposals to introduce major changes to the management and work of the European Community's Joint Research Centre (JRC) - which runs laboratories at four separate sites - are due to be announced later this month, officials in Brussels have confirmed. The JRC's role in the Community's research programme has come under close scrutiny during the past year, particularly throughout the prolonged deliberations over the size of the budget for the five-year research and development 'Framework' programme. Shortly after the programme was officially ratified at the end of last month (see Nature 329, 381 ; 1987), Karl-Heinz Narjes, the commissioner with responsibility for technology, told a private meeting of research ministers that reform of the JRC would be announced imminently, with particular emphasis on a less rigid management structure, a review of the inflexible "multiannual' system of research planning and greater collaboration with industry, both to earn money by contract work and through 'industrial clubs' to ensure a greater degree of 'relevance' in the research. It is understood that the Commission wants to see the JRC earning around 40 per cent of its own income by 1990.

Reform of the JRC is seen as a way of appeasing critics of the Community's research programme, particularly Britain and West Germany, the two countries largely responsible for the delay in approving the Framework budget. But even the more sympathetic member states agree that a shake-up is due. The JRC was set up under the Euratom treaty as a nuclear research centre, becoming operational in 1960-61. Most of the expertise is in nuclear matters, although the scope of its work has expanded more recently to include such fields as remote sensing and the study and protection of the environment. The JRC comprises four separate establishments, at Ispra in Italy, Petten in The Netherlands, Geel in Belgium and Karlsruhe in West Germany.

The grounds for a reorganization were laid last year with the publication of the JRC's mid-term evaluation report by the Commission's scientific council. That report condemned the multiannual programme system as imposing "stifling rigidity". Decision-making procedures were "complex and ponderous" and although most of the research activities were of "generally good quality", the JRC needed to increase its links with outside institutions, including industry.

A report from an independent panel of prominent European industrialists was also commissioned. The report, presented to the European Commission earlier this year, remains unpublished but is known to have been critical of the management and research priorities of the JRC, particularly at Ispra which accounts for three-quarters of the total JRC budget and staff.

This year the JRC will receive approximately 200 million European Currency Units ( 1 ECU $=£ 0.69$ ), of which 21
Tokyo

SUPERCONDUCTORS and murder? When the body of a Hiroshima University professor who specialized in superconductor research was found on the floor of his office in late July with knife wounds in the back, it was speculated that intense rivalry in the race to develop high-temperature superconductors lay behind the incident. But although the new superconductors played an indirect role, it now appears that the murder had more to do with appointment practices and the problem of 'permanent assistants' in Japan's national universities.

Dr Hiroshi Suemitsu, an assistant in elementary particle physics in Hiroshima University's Faculty of Integrated Arts and Sciences, has confessed to killing his professor, Tetsuhiko Okamoto, dean of the faculty, for passing him over for promotion. At a faculty meeting in July, it was decided that two posts to be vacated by associate professors of elementary particle physics in February next year will be filled by material scientists, including a specialist in the new superconducting ceramics. For Suemitsu this was the final straw in his 17-year struggle to climb above the first rung of the academic ladder.

Joshu, or assistant in Japanese, literally means 'helping hand', and some professors interpret the term that way, assigning all sorts of menial tasks to their assistants. But the post carries no teaching responsibilities, and, apart from professional chores, assistants are free to carry on research, albeit with very limited funds.

As civil servants, joshu are entitled to lifelong employment, and, although the salary is below the national average, some of Japan's assistants seem content with their lot. As one Tokyo University assistant put it, "there are essentially two species of joshu: those who see the post as a stepping stone to an associate professorship and beyond, and those who seem to have settled for life". But even the former million ECU will come from sources other than the JRC programme budget (most of it is accounted for by 14.5 million ECU from the West German and Dutch governments' contribution to the high-flux reactor project at Petten). While officials maintain that much of the criticism of the JRC is unfair, they concede that the JRC's outside earnings are 'marginal' and that there is considerable scope for improvement. The total staffing level of 2,260 is likely to remain the same, although the need for new blood has been stressed and is likely to be reflected in any new recruitment policy.Simon Hadlington

\title{
Permanent assistant's frustration leads to professor's murder
}

species often get stuck on the first stone many of the approximately 17,500 assistants in Japan's national universities are in their $40 \mathrm{~s}$. And the problem of 'permanent assistants' is a major headache for the Ministry of Education, Science and Culture, their employee.

From his confession, it is clear that Suemitsu was seeking promotion. He graduated from Hiroshima University in March 1966 and was appointed as an assistant in 1970 before completing his doctorate in 1972. At that time, Hiroshima University faculty were drawn almost exclusively from the ranks of the university's own graduates, a situation that still prevails in many of Japan's national universities. But following the student riots of the early 1970s, Hiroshima University underwent a major reorganization and in 1974 Suemitsu was placed in the new Faculty of Integrated Arts and Sciences, which has a more open and flexible appointment system. After the reorganization, the university received a flood of appointees from other universities such as Tokyo and Nagoya. So for Hiroshima graduates such as Suemitsu, competition for faculty places became even fiercer.

Moves are being made to try and cope with the problem of permanent assistants. For example, at Tokyo University's Institute of Solid State Physics, there is an understanding that assistants should move on, either up the academic ladder or out of the institute, after about five years, according to Shuntaro Watanabe, an associate professor at the institute. But the problem is deep-rooted and can be traced to the expansion of the universities in the 1960 s which created a huge population of PhD holders with no posts for them to fill (see Nature 309,659 ; 1984). A decision to expand the universities seems most unlikely in the current climate of government financial restraint and as long as faculty enjoy lifelong employment, the assistants can only sit and wait for their superiors to retire.
David Swinbanks 